\title{
Awareness of human papilloma virus (HPV) vaccine female doctors working in tertiary care centres.
}

\footnotetext{
1. MBBS, FCPS

Assistant Professor

Lahore General Hospital/ PGMI/

Ameer ud Din Medical College,

Lahore.

2. MBBS, FCPS

Medical Officer

Jinnah Hospital, Lahore.

3. MBBS, DGO, MCPS, FCPS, MPHE

Professor Gyne \& Obs

Services Hospital, Lahore.
}

Correspondence Address:

Dr. Zahra Safdar

Assistant Professor Gyne \& Obs

Lahore General Hospital/

PGMI/Amer-ud-din Medical College.

zsafdar2@gmail.com

Article received on:

08/09/2020

Accepted for publication:

25/01/2021

\begin{abstract}
Zahra Safdar $^{1}$, Faisal Ashraf ${ }^{2}$ Alia Bashir ${ }^{3}$
\end{abstract}
ABSTRACT... Objectives: The aim of the study is to assess the awareness about various aspects of HPV infection and vaccine among female doctors working in tertiary care centres. Study Design: Cross Sectional study. Setting: 3 Tertiary Care Hospitals Lahore. Period: Jan 2018 Jan 2019. Material \& Methods: 478 female doctors from 03 tertiary care hospitals (Lady Atchison hospital, Lahore General Hospital and Services Institute of Medical Sciences) in Lahore who voluntarily filled 18-point self-administered questionnaire assessing their knowledge about HPV infection (8) HPV vaccine (5) and opinions about it (5). Knowledge score (range 0-8), assuming adequate knowledge $>$ median. Factors associated with opinions were explored and analysed. Results: Most replied knowledge questions correctly $67.2 \%, 39.5 \%$ perceived it as frequently occurring infection. Median knowledge was 6 out of 8 questions; lack of knowledge was associated with non ob-gynae speciality or junior level. None of the participants were immunized but $46.3 \%$ were willing to get vaccinated themselves $78.1 \%$ were willing to get their daughters vaccinated. Self-perceived under exposure of HPV infection was $67.9 \%$. Lack of feeling it as important in our social setting (28.6\%), and expensiveness (19.4\%) were most common causes of not counselling the patient about HPV vaccine and counselling to get vaccinated was most commonly done as it saves patients from cervical cancer (86.8\%). Conclusions: Despite adequate knowledge of HPV infection and effectiveness of its vaccination, female doctors working in tertiary care hospitals of Lahore's are not efficiently spreading awareness to the society and prescription of the vaccination is also deficient.

Key words: $\quad$ Awareness, Cervical Cancer, HPV, Medical Professionals, Vaccination.

Article Citation: Safdar Z, Ashraf F, Bashir A. Awareness of human papilloma virus (HPV) vaccine female doctors working in tertiary care centres. Professional Med J 2021; 28(4):464-469. https://doi.org/10.29309/TPMJ/2021.28.04.6067

\section{INTRODUCTION}

Human papilloma viruses (HPV) are common pathogens disseminating through sexual intercourse. ${ }^{1}$ Several genotypes are identified and classified in low and high risk types depending on their oncogenic potential. ${ }^{2}$ Low risk genotypes are associated with anogenital warts while high risk, with cervical cancer. ${ }^{3,4}$

Sexually active individuals are $75 \%$ prone to get infected but several factors like age, social norms and sexual behaviour influence its incidence. ${ }^{5}$ Consequently, its prevalence is low among conservative societies with strict sexual relationships. Despite the society norms HPV infection is at rise in Pakistan and $>90 \%$ of cervical cancers diagnosed in Pakistan are HPV positive. ${ }^{6}$ Cervical cancer has alarmingly become second most common cancer in females between 15-44 years in Pakistan. ${ }^{7}$

Global strategy in cervical cancer prevention includes HPV cervical screening and HPV vaccination. ${ }^{8}$ The developed nations have included HPV vaccination programs and recommend preventive vaccination to adolescents as a routine. ${ }^{9}$ They recommend HPV vaccine to females and males unexposed to sexual intercourse between 13-26 years and 13-21 years, respectively. The preventive vaccination programs have shown rapid efficiency in developed world. ${ }^{10}$

The preventive HPV vaccination program in Pakistan is unheard of and lack of finances has made the strategical implementation of this program even impossible. Lack of cost 
effectiveness is another major factor which has made HPV vaccination rather unpopular. ${ }^{11}$ But the role of preventive measures against cervical cancer in general population as well as high risk groups is vital. ${ }^{12}$

Awareness of physicians as well as general population has role which needs to be stressed upon. ${ }^{13}$ Knowledge of rising prevalence of the problem will influence the influencers as well as masses, increasing the acceptability and utilization of an effective preventive method; HPV vaccination. ${ }^{14}$ Female doctors play an important role in influencing mothers in making conscious decision about their next generation. Assessing their knowledge, acceptability and opinion about HPV vaccine can be game changing. ${ }^{15}$ Hence, we attempted to assess the knowledge, acceptability and opinion of female doctors working in tertiary care centres of Lahore, Pakistan.

\section{MATERIAL \& METHODS}

A cross sectional study was conducted from January 2018 to January 2019 in randomly selected 03 tertiary care hospitals (Lady Atchison hospital, Lahore General Hospital and Services Institute of Medical Sciences) in Lahore, Pakistan in doctors who voluntarily filled 18-point selfadministered questionnaire assessing their knowledge about HPV infection (8) HPV vaccine (5) and opinions about it (5). Knowledge score (range 0-8), assuming adequate knowledge > median. Factors associated with opinions were explored and analysed. A self-administered 18-point questionnaire was handed over to randomly select female doctors with valid Pakistan Medical and Dental Council certification after taking informed consent about confidentiality and anonymity.

\section{Inclusion Criteria}

1. Participants were randomly selected female doctors

2. Working in any of the 03 tertiary care hospitals listed,

3. Having a valid Pakistan Medical and Dental Council Registration

\section{Exclusion Criteria}

1. Non- female doctor

2. Not having valid Pakistan Medical and Dental Council Registration

3. Who didn't volunteer to participate in study

The questionnaire had four domains; the first domain included the age, medical speciality and level of experience. The second domain included 8 knowledge question regarding HPV infection, third domain has 5 questions regarding HPV vaccine and fourth domain included 5 questions about their opinion about HPV vaccination.

The statistical analysis was done with SPSS v.20, the variables such as doctor's characteristics, their response to knowledge and perception questions were described in frequencies and percentages. Individual knowledge questions were analysed with correct $=1$ and incorrect $=0$, then summated before percentages were calculated in two domains of knowledge. Identification of factors associated with recommendation of HPV vaccine was carried out with binary logistic regression model. Statistical significance was set as $\mathrm{P}$-value $<$ 0.05 .

\section{RESULTS}

478 female doctors filled a printed questionnaire with median age group of 30-34 years. Ob-gynae doctors were $61 \%$, internal medicine doctors were $22.8 \%$ while surgery doctors were $5.8 \%$, and radiology doctors were $5.5 \%$ while those working in emergency department were $4.6 \%$. $31 \%$ were consultants, $56 \%$ were post graduate residents out of which first year residents were $26 \%$, second years were $18 \%$, third year residents were $31 \%$ - and fourth-year residents were $25 \%$ while $13 \%$ were house officers. Not a single doctor recruited in the study herself was vaccinated but $46.3 \%$ were willing to get themselves vaccinated while $78.1 \%$ were willing to get their off springs vaccinated. $2.4 \%$ recommend their patients to get vaccinated while $67.9 \%$ self-perceive that HPV infection is rare in our society, $28.6 \%$ don't feel it as important in our society setting to recommend HPV vaccination. $19.4 \%$ think vaccination is expensive so do not recommend it. 


\begin{tabular}{|c|c|c|}
\hline No. & Age (years) & Doctors \\
\hline 1. & $20-24$ & 73 \\
\hline 2. & $25-29$ & 118 \\
\hline 3. & $30-34$ & 189 \\
\hline 4. & $35-39$ & 67 \\
\hline 5. & $40-45$ & 25 \\
\hline
\end{tabular}

Table-I. Characteristics of female doctors. (Age Group).

\begin{tabular}{|c|c|c|c|}
\hline No. & Speciality & $\begin{array}{c}\text { Number } \\
\text { of } \\
\text { Doctors }\end{array}$ & $\begin{array}{c}\text { Percentage } \\
\text { (\%) }\end{array}$ \\
\hline 1. & Obstetrics \& gynae & 288 & 61 \\
\hline 2. & Internal medicine & 108 & 22.8 \\
\hline 3. & General surgery & 28 & 5.8 \\
\hline 4. & Radiology & 26 & 5.5 \\
\hline 5. & Emergency department & 22 & 4.6 \\
\hline
\end{tabular}

Table-I (b). Speciality.

\begin{tabular}{|c|c|c|c|}
\hline No. & Level of expertise & $\begin{array}{c}\text { Number of } \\
\text { Doctors }\end{array}$ & \%age \\
\hline 1 & Consultants & 146 & 31 \\
\hline 2 & $\begin{array}{c}\text { Post-graduate (PG) } \\
\text { residents }\end{array}$ & 264 & 56 \\
\hline a. & PG1 & 66 & 25 \\
\hline b. & PG2 & 82 & 31 \\
\hline c. & PG3 & 47 & 18 \\
\hline d. & PG4 & 69 & 26 \\
\hline 3. & House officers & 62 & 13 \\
\hline
\end{tabular}

Table-I (c). Level of expertise.

\begin{tabular}{|c|c|c|}
\hline No. & Statement & $\begin{array}{c}\text { Percentage Willing } \\
\text { (\%) }\end{array}$ \\
\hline 1. & $\begin{array}{c}\text { Doctors already } \\
\text { vaccinated against HPV }\end{array}$ \\
\hline 2. & $\begin{array}{c}\text { Doctors willing to get } \\
\text { vaccinated themselves }\end{array}$ \\
\hline 3. & $\begin{array}{c}\text { Doctors willing to get their } \\
\text { offspring vaccinated }\end{array}$ \\
\hline & Table-II. Willingness for HPV vaccination. \\
\hline
\end{tabular}

\begin{tabular}{|c|c|c|}
\hline No. & Reason & $\begin{array}{c}\text { Percentage } \\
\text { (\%) }\end{array}$ \\
\hline 1. & It saves against cervical cancer & 86.8 \\
\hline 2. & It is service to humanity & 13.2 \\
\hline \multicolumn{2}{|c|}{ Table-Il (a). Reasons for prescribing HPV vaccine. } \\
\hline
\end{tabular}

Professional Med J 2021;28(4):464-469.

\begin{tabular}{|c|c|c|}
\hline No. & Reason & $\begin{array}{c}\text { Percentage } \\
\text { (\%) }\end{array}$ \\
\hline 1. & You don't feel it's important in & 28.6 \\
\hline 2. & our society & 19.4 \\
\hline 3. & It is expensive & 18.7 \\
\hline 4. & Not available in Pakistan & 15.1 \\
\hline 5. & $\begin{array}{c}\text { You don't are not interested in } \\
\text { vaccination }\end{array}$ & 18.2 \\
\hline
\end{tabular}

Table-II (b). Reasons for not prescribing HPV vaccine.

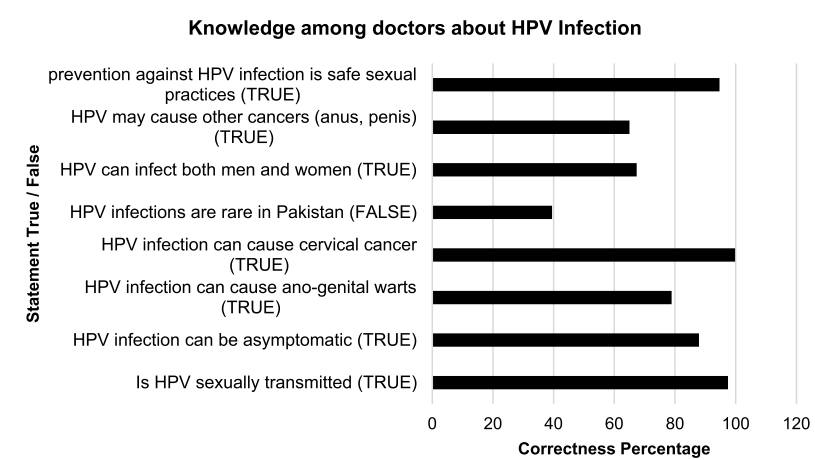

\section{(A)}

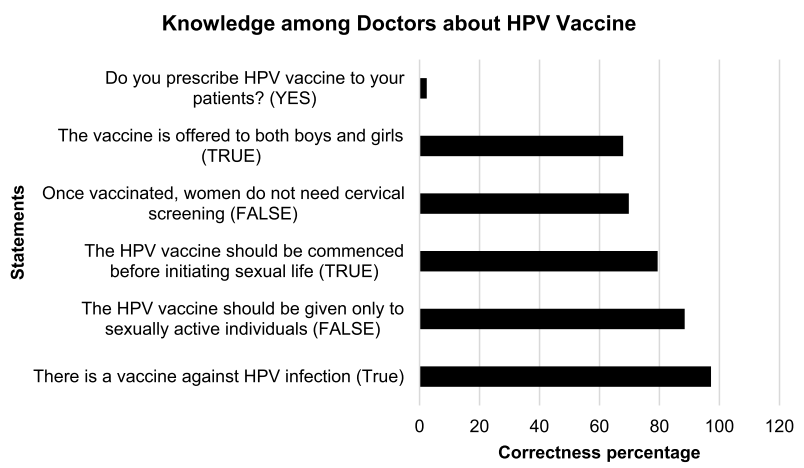

(B)

Figure-1. A\&B Knowledge of HPV infection among doctors.

\section{DISCUSSION}

The rising prevalence of HPV infection in adult population in conservative societies is relatively new entity. ${ }^{6}$ Multiple studies advocate rise of HPV infection in Saudi ${ }^{16}$ as well as in Kuwaiti population. ${ }^{17}$ Indian studies also have similar interpretation about HPV prevalence. ${ }^{18}$ The benign issues associated with human papilloma virus like anogenital warts are self-resolving in $90 \%$ of cases. ${ }^{19}$ The strong causal relationship of cervical cancer with HPV infection brought HPV viruses in 
limelight. ${ }^{20}$ The incidence of cervical cancer is at rise in Pakistan and recent studies make it second most common malignancy in females between $15-44$ years of age. ${ }^{21}$ This is an alarming statement and prevention of this malignancy becomes even more important as it is effecting young population. ${ }^{22}$ The preventive methods present are effective cervical cancer screening and HPV preventive vaccination. ${ }^{23}$ The cervical screening programs implemented in developed have been a successful step and they have implemented HPV preventive vaccination among young girls between 11-12 years as well. The results are even more promising in studies. Cervical cancer screening programs have already been successful in developed world and developing world has already accepted its importance. ${ }^{24}$ But the role of HPV preventive vaccination is still not widely accepted. This study out in Lahore, a provincial capital in Pakistan, preventive measure was assessed in our society among female doctors, who was themselves working in most developed centres in a developed city of Pakistan where the availability of HPV preventive vaccination was ensured. The mean age of participants was $32 \pm$ 3.6 years. The age ranges between 24 years and 43 years. The group of doctors selected were females themselves so that a gender bias could be excluded and their knowledge was assessed with 8 knowledge questions. Half of doctors had all their questions correct $(47.8 \%)$, most of them had 6 out 8 questions correct (67.2\%) which was taken as median knowledge. Many similar studies among health workers in Pakistan assessing their knowledge on HPV infection have similar results. Many studies conducted in South Asian countries also advocate adequate knowledge among doctors, nurses and medical students. ${ }^{25}$ Lack of knowledge was associated in junior doctors i.e. house officers (34.6\%) and junior doctors working in non ob-gynae specialities. But overall, most of doctors were found to be knowledgeable.

The next step of study was to assess the implantation of knowledge to get them vaccinated. None were already vaccinated but $46.3 \%$ of the doctors in the study were willing to get themselves vaccinated. A similar study from
India shows comparable results in willingness of self-vaccination. ${ }^{26}$ However some studies from Nepal and Bangladesh show lower degree of knowledge and acceptance of HPV vaccine. ${ }^{27}$ Acceptance of vaccine among participants was assessed by asking them if they were willing to get their daughters vaccinated and the results were overwhelming. $78.1 \%$ were willing to get their daughters vaccinated. The next step was to assess their acceptability by asking if they prescribed the vaccine to their patients. Female doctors are closer to female patients and can counsel them for issues with sexual association. Despite adequate knowledge only a mere $2.4 \%$ were already prescribing the vaccination to their patients. $86.8 \%$ of the doctors prescribing vaccination were ob-gynae consultants and almost all were prescribing as it was preventive of cervical cancer. The problem of implementation of vaccination program was identified to be at this point that cervical cancer prevention with vaccination is not propagated by health care workers not even female doctors and not even those working in tertiary care centres. The knowledge and acceptability were not being contributed towards prescription and propagation of HPV vaccine. This was a major contributor to lack of vaccination among masses. As the health care workers are not contributing towards counselling for it neither are, they prescribing it? This aspect needs attention from authorities as well as pharmaceutical companies addressing this issue. The major reasons given by the participants were self-perceived knowledge of under exposure of HPV infection (67.9\%). This aspect of misconception among doctors working in large setups is alarming and is very misleading in propagation of information to masses regarding importance of HPV vaccination. Lack of feeling it as important in our social setting is also $28.6 \%$ so they don't find it important to recommend it and counsel the patients for it, which is also not a good predictor of doctors taking HPV infection seriously and $19.4 \%$ of doctors do not prescribe the HPV vaccine as it is expensive. Cost of the vaccine for the community is an important factor for it not being available widely for prescription by doctors individually as well as by the government as a whole as a preventive method against 
rising cervical cancer in our society. The mass vaccination and inclusion of HPV vaccine in our national vaccination program is a big step to be taken if we want serious steps towards decreasing prevalence of cervical cancer in our country. In this study, it was found that only $2.4 \%$ of participants were prescribing HPV vaccine to their patients and major reason behind their prescription was that the vaccination saves the patients from cervical cancer (86.8\%). Despite adequate knowledge and awareness, the attitude of female doctors towards this serious issue is lacking seriousness and persistence. The seriousness of the matter can be extracted from data of cervical cancer in Pakistan in last few years. In a study analysing data from Pakistan, $70 \%$ of the females with cervical cancer report in advanced stage. ${ }^{7}$ Early diagnosis and preventive measures are much needed at this stage in our country and doctors play a key role in spread of awareness about it.

The limitation of the study turned out to be that it was conducted in urban area of the country and the participants of the study were those working in well-developed health organizations. The perspective taken in the study although is from a large number of participants but is not representative of the health care workers from rural areas of the country not even represents everyone working in primary or secondary health care setups.

\section{CONCLUSION}

The doctors despite having knowledge about HPV infection and its vaccination are not prescribing it to their patients. Massive campaign among general public as well as the health care professionals are necessary to sensitise the community. Print and social media should be the key to reach out to the young masses, which are potential affected. The government should also play their role by including HPV vaccination in the extended program of vaccination.

Copyright(C 25 Jan, 2021.

\section{REFERENCES}

1. Longworth MS, Laimins LA. Pathogenesis of human papillomaviruses in differentiating epithelia. Microbiol Mol Biol Rev. 2004; 68(2):362-72.

2. Stoler MH, Wright TC, Parvu V, Yanson K, Eckert K, Kodsi $S$, et al. HPV testing with 16, 18, and 45 genotyping stratifies cancer risk for women with normal cytology. Am J Clin Pathol. 2019; 151(4):433-42.

3. Malgave DS, Pratinidhi SA. A study of awareness of human papilloma virus vaccine in a teaching hospital. Indian Journal of Medical Specialities. 2015; 6(1):4-7.

4. Thompson EL, Wheldon CW, Rosen BL, Maness SB, Kasting ML, Massey PM. Awareness and knowledge of HPV and HPV vaccination among adults ages 2745 years. Vaccine. 2020; 38(15):3143-8.

5. Alotaibi HJ, Almajhdi FN, Alsaleh AN, Obeid DA, Khayat $\mathrm{HH}$, Al-Muammer TA, et al. Association of sexually transmitted infections and human papillomavirus co-infection with abnormal cervical cytology among women in Saudi Arabia. Saudi Journal of Biological Sciences. 2020; 27(6):1587-95.

6. Maness SB, Reitzel LR, Watkins KL, McNeill LH. HPV awareness, knowledge and vaccination attitudes among Church-going African-American Women. Am J Health Behav. 2016; 40(6):771-8.

7. Batool SA, Sajjad S, Malik H. Cervical cancer in Pakistan: A review. JPMA the Journal of the Pakistan Medical Association. 2017; 67(7):1074-7.

8. Kessler TA. Cervical cancer: Prevention and early detection. Seminars in Oncology Nursing. 2017; 33(2):172-83.

9. Harper DM, DeMars LR. HPV vaccines - A review of the first decade. Gynecologic Oncology. 2017; 146(1):196-204.

10. Vorsters A, Arbyn M, Baay M, Bosch X, de Sanjosé $S$, Hanley $S$, et al. Overcoming barriers in HPV vaccination and screening programs. Papillomavirus Research. 2017; 4:45-53.

11. Khan TM, Buksh MA, Rehman IU, Saleem A. Knowledge, attitudes, and perception towards human papillomavirus among university students in Pakistan. Papillomavirus Research. 2016; 2:122-7.

12. Khan M, Zafar A, Muneer R, Siddiqui AA. Awareness regarding pap smear among female University Students of Karachi: A cross-sectional survey. Cureus. 2018; 10(6):e2784-e. 
13. Almazrou S, Saddik B, Jradi H. Knowledge, attitudes, and practices of Saudi physicians regarding cervical cancer and the human papilloma virus vaccine. Journal of Infection and Public Health. 2020; 13(4):58490.

14. Padmanabha $N$, Kini JR, Alwani AA, Sardesai A. Acceptability of human papillomavirus vaccination among medical students in Mangalore, India. Vaccine. 2019; 37(9):1174-81.

15. Vorsters A, Bonanni P, Maltezou HC, Yarwood J, Brewer NT, Bosch FX, et al. The role of healthcare providers in HPV vaccination programs - A meeting report. Papillomavirus Research. 2019; 8:100183.

16. Jradi H, Bawazir A. Knowledge, attitudes, and practices among Saudi women regarding cervical cancer, human papillomavirus (HPV) and corresponding vaccine. Vaccine. 2019; 37(3):530-7.

17. Obeid DA, Almatrrouk SA, Alfageeh MB, Al-Ahdal MNA, Alhamlan FS. Human papillomavirus epidemiology in populations with normal or abnormal cervical cytology or cervical cancer in the Middle East and North Africa: A systematic review and meta-analysis. Journal of Infection and Public Health. 2020; 13(9):130413.

18. Del Mistro A, Frayle $H$, Menegaldo A, Favaretto $N$, Gori S, Nicolai $P$, et al. Age-independent increasing prevalence of Human Papillomavirus-driven oropharyngeal carcinomas in North-East Italy. Scientific Reports. 2020; 10(1):9320.

19. Cubie HA. Diseases associated with human papillomavirus infection. Virology. 2013; 445(1):21-34.

20. Crosbie EJ, Einstein MH, Franceschi S, Kitchener HC. Human papillomavirus and cervical cancer. The Lancet. 2013; 382(9895):889-99.
21. Khan S, Jaffer NN, Khan MN, Rai MA, Shafiq M, Ali A, et al. Human papillomavirus subtype 16 is common in Pakistani women with cervical carcinoma. International Journal of Infectious Diseases. 2007; 11(4):313-7.

22. Faridi R, Zahra A, Khan K, Idrees M. Oncogenic potential of Human Papillomavirus (HPV) and its relation with cervical cancer. Virology Journal. 2011; 8(1):269.

23. Lees BF, Erickson BK, Huh WK. Cervical cancer screening: Evidence behind the guidelines. American Journal of Obstetrics and Gynecology. 2016; 214(4):438-43.

24. Flores YN, Salmerón J, Glenn BA, Lang CM, Chang LC, Bastani R. Clinician offering is a key factor associated with HPV vaccine uptake among Mexican mothers in the USA and Mexico: A cross-sectional study. International Journal of Public Health. 2019; 64(3):32332.

25. Brisson M, Kim JJ, Canfell K, Drolet M, Gingras G, Burger EA, et al. Impact of HPV vaccination and cervical screening on cervical cancer elimination: A comparative modelling analysis in 78 low-income and lower-middle-income countries. The Lancet. 2020; 395(10224):575-90.

26. Kaarthigeyan K. Cervical cancer in India and HPV vaccination. Indian $\mathrm{J}$ Med Paediatr Oncol. 2012; 33(1):7-12.

27. Sankaranarayanan R, Bhatla N, Gravitt PE, Basu P, Esmy $\mathrm{PO}$, Ashrafunnessa KS, et al. Human papillomavirus infection and cervical cancer prevention in India, Bangladesh, Sri Lanka and Nepal. Vaccine. 2008; 26:M43-M52.

\begin{tabular}{|c|c|c|c|}
\hline \multicolumn{4}{|c|}{ AUTHORSHIP AND CONTRIBUTION DECLARATION } \\
\hline Sr. \# & Author(s) Full Name & Contribution to the paper & Author(s) Signature \\
\hline 2 & $\begin{array}{l}\text { Zahra Safdar } \\
\text { Faisal Ashraf } \\
\text { lia Bashir }\end{array}$ & $\begin{array}{l}\text { Data collection, Statistical analysis, } \\
\text { Article writing, Correspondence. } \\
\text { Data collection. } \\
\text { Data collection, Performa making } \\
\text { helping in con }\end{array}$ & Alia Bashior \\
\hline
\end{tabular}

